\title{
INOVAÇÃO SOCIAL: UMA REVISÃO BIBLIOGRÁFICA DOS ESTUDOS DE CASO PUBLICADOS NO BRASIL
}

\section{SOCIAL INNOVATION: A BIBLIOGRAPHIC REVIEW OF THE CASE STUDIES PUBLISHED IN BRAZIL}

\author{
Ronalty Oliveira Rocha \\ Universidade Federal de Sergipe - UFS \\ ronaltyrocha@gmail.com \\ Aline França de Abreu \\ Universidade Federal de Sergipe - UFS \\ afdeabreu@gmail.com \\ Debora Eleonora Pereira da Silva \\ Universidade Federal de Sergipe - UFS \\ dsilva.ufs@gmail.com \\ Maria Elena Leon Olave \\ Universidade Federal de Sergipe - UFS \\ mleonolave@gmail.com
}

Submissão: 13/11/2018

Aprovação: 18/12/2019

\section{RESUMO}

Este trabalho teve como objetivo analisar como a inovação social tem sido caracterizada nos estudos brasileiros. Apresenta-se um recorte da inovação social nos estudos de caso brasileiros disponibilizados nas bases de dados SPELL e anais da ANPAD. Identificaram-se 21 artigos em periódicos e 16 em eventos da ANPAD. Os estudos selecionados foram analisados à luz das dimensões de inovação social propostas por Tardif e Harrisson (2005) Transformação, caráter inovador, inovação, atores e processo. Ao todo foram selecionados e analisados 37 artigos, publicados entre janeiro de 2007 e agosto de 2019. De modo geral, as evidências encontradas apontam que os estudos de caso brasileiros sobre inovação social consideram as dimensões propostas por Tardif e Harrisson (2005), contudo nem todos os artigos apresentam em totalidade, nem mesmo descrevem, adequadamente, as 5 dimensões propostas por esses autores Destaca-se especialmente as dimensões de transformação e processos dentre as menos explicadas nos estudos consultados.

Palavras-chave: Inovação social. Dimensões de inovação social. 
ABSTRACT

This paper aimed to analyze how social innovation has been characterized in Brazilian studies. A snippet of social innovation is presented in the Brazilian case studies available in the SPELL and anal databases of ENANPAD. We identified 21 articles in journals and 16 in ANPAD events. The selected studies were analyzed in light of the dimensions of social innovation proposed by Tardif and Harrisson (2005) - Transformation, innovative character, innovation, actors and process. In all, 37 articles were selected and analyzed, published between January 2007 and August 2019. In general, the evidence found indicates that Brazilian case studies on social innovation consider the dimensions proposed by Tardif and Harrisson (2005), however neither All articles present in full, do not even adequately describe the 5 dimensions proposed by these authors. Particularly noteworthy are the dimensions of transformation and processes among the least explained in the studies consulted.

Keywords: Social innovation. Dimensions of social innovation.

\section{INTRODUÇÃO}

Onde as organizações, governos e entidades privadas, são lentas ou não agem para apoiar os desafios da comunidade, estão sendo buscadas iniciativas para resolver disparidades sociais, bem como para liberar recursos para a comunidade através da busca por inovações sociais que contribuam para melhorar o bem-estar social (DAWSON; DANIEL, 2010).

A inovação social tem sido apresentada como a criação de novas formas organizacionais e institucionais, assim como novas práticas sociais, novas abordagens e novos conceitos que promovam reais e concretas melhorias na qualidade de vida dos indivíduos (CRISES, 2004).

Em função de seu "apego" a melhoria da qualidade de vida, a inovação social ganhou expressividade nos últimos anos impulsionada pelo interesse em questões sociais por determinados segmentos da sociedade (CAJAIBA; SANTANA, 2014).

Contudo, academicamente, não existe, ainda, entendimento sobre o verdadeiro significado e relevância da inovação social enquanto campo de pesquisa (POL; VILLE, 2009). Have e Rubalcaba (2016) complementam que a inovação social ainda é retratada em diversos ângulos, abordagens e cortes analíticos, o que faz desse tema um grupamento de tratamentos, metodologias e práticas que ainda não se constituíram num corpo consistente e integrado de conhecimentos como campo de pesquisas.

Especialmente no Brasil, conforme destaca Patias et al., (2015) a inovação social ainda é um campo de pesquisas com abundância de oportunidades e análises acadêmicas, em razão do expressivo espaço para contribuições teóricas e práticas. Por essa razão este estudo adotou como objetivo analisar como a inovação social tem sido caracterizada nos estudos de casos no Brasil, assim como quais as dimensões têm sido consideradas delimitadoras ao tema.

Para alcance do objetivo proposto, esse estudo contemplou uma revisão bibliográfica das publicações do tipo estudo de caso, divulgadas nas bases do Scientific Periodicals Electronic Library (SPELL) e da Associação Nacional de Pós-Graduação e Pesquisa em Administração (ANPAD), e as analisou à luz das dimensões de inovação social transformação, caráter inovador, inovação, atores e processo - propostas por Tardif e Harrisson (2005).

O trabalho de Tardif e Harrisson (2005) tem sido utilizado como uma das principais referências para discussão sobre inovação social, tendo sido, extensamente, debatido, aprofundado e replicado (GOMÉZ et al., 2015), e por essa razão adotado como modelo de análise nesse estudo. 
A escolha da estratégia de estudo de caso como requisito ao estudo da inovação social foi feita em conformidade com Silva et al., (2016) que detectaram que o estudo de caso é o procedimento técnico mais utilizado em teses da área de administração, uma vez que esta estratégia metodológica contempla um retrato com profundidade sobre fenômenos de diversas naturezas.

Silva et al., (2016) destacam também que a predominância da estratégia de estudos de casos em pesquisas qualitativas é justificada pela larga possibilidade de analisar teorias no contexto prático das organizações. Razão adicional para a seleção da estratégia de estudo de caso foi a constatação de que este é o método mais utilizado em pesquisas na área de administração no Brasil (LOBLER, LEHART, AVELINO, 2014).

Acrescenta-se a relevância do estudo sobre inovação social em razão da insuficiência, no Brasil, de pesquisas teóricas e empíricas sobre o tema (BATAGLIN, 2017). Além disso, Pue, Vandergeest e Breznitz (2016), assim como por Ribeiro et al., (2019) defendem que a inovação social oferece consistente colaboração na resolução de problemas sociais, econômicos e tecnológicos.

Esse entendimento é corroborado por Cordeiro (2019) que argumenta que a inovação social promove a transformação social a partir da participação e inclusão dos menos favorecidos na sociedade, de modo que, além da importância acadêmica, o tema inovação social tem grande expressão prática (CORDEIRO, 2019).

Para melhor exposição do tema proposto, e em razão do objetivo definido, esse estudo foi dividido em 5 partes. A primeira delas foi essa introdução apresentando, brevemente, que a inovação social ainda não se apresenta como um campo de estudos consolidado, a segunda parte apresenta uma revisão bibliográfica dos principais conceitos e dimensões atrelados à inovação social.

A terceira seção constitui-se da apresentação dos procedimentos metodológicos (operacionais), ao passo em que a quarta seção analisa os estudos selecionados conforme as dimensões apresentadas por Tardif e Harrisson (2005). Por fim a conclusão apresenta a síntese e inferências sobre os resultados obtidos, assim como sugestões para estudos futuros.

\section{INOVAÇÃO SOCIAL}

A expressão inovação social foi, inicialmente, assinalada nos primeiros anos do século XXI, no trabalho de Taylor (1970), e, aceleradamente, ganhou espaço nas discussões de estudiosos sobre inovação (CLOUTIER, 2003). A inovação social ganhou expressividade em razão da insuficiência das estruturas e políticas existentes para eliminação de problemas sociais e surgiu como uma reação aos complexos desafios sociais, ambientais e demográficos (WARNOCK, 2014) não atendidos pela ação governamental.

De modo mais abrangente, a inovação social é caracterizada como um plano de mudanças efetivado pela operacionalização de ideias capazes de melhorar a qualidade de vida da população e promover mudança social (CAJAIBA-SANTANA, 2014; POL; VILLE, 2009), criando, assim, novas e duradouras soluções para demandas e carências sociais não atendidas (LUBELCOVÁ, 2012).

Dessa maneira, a inovação social é fruto do conhecimento acumulado e investido por indivíduos, organizações e entes públicos para solucionar necessidades sociais e promover transformações sociais sistêmicas (WESTLEY; ANTADZE, 2010), através da participação e cooperação de diversos atores sociais, mediante a criação e inserção de produtos, serviços e modelos para problemas que assolam grupos, comunidades e/ou a sociedade em geral (MURRAY et al., 2010; LACERDA; FERRARINI, 2013).

Logo, conforme é sintetizado por André e Abreu (2006) a inovação social é caracterizada em três atributos: (I) satisfação de necessidades humanas não satisfeitas pelo 
mercado e governos; (II) promoção da inclusão social; e (III) capacitação de indivíduos expostos a processos de exclusão e/ou marginalização. Isto é, a inovação social comporta um caráter coletivo capaz de promover transformações nas relações sociais. Esse entendimento é ratificado por Fleury (2011) que destaca a inovação social como instrumento para ampliação da cidadania e atenuação da exclusão social.

A melhor compreensão do conceito de inovação social passa pela adequada distinção desta com os conceitos de inovação tecnológica. Inicialmente, André e Abreu (2006) expõem que a distinção da inovação comercial e/ou tecnológica está na gênese do conceito de inovação social. Os autores explicam que a inovação tecnológica surge com o intuito de alcançar maiores lucros e evitar ameaças da concorrência, ao passo em que a inovação social surge pela necessidade de vencer dificuldades e riscos aos quais parte da população está exposta.

Bignetti (2011) define cinco pontos pelos quais a inovação social se distingue da inovação tecnológica, conforme apresentado no Quadro 1.

Quadro1 - Diferenças entre inovação tecnológica e inovação social

\begin{tabular}{|l|l|l|}
\hline \multicolumn{1}{|c|}{$\begin{array}{l}\text { Elemento } \\
\text { distintivo }\end{array}$} & \multicolumn{1}{|c|}{ Tecnológica } & \multicolumn{1}{c|}{ Social } \\
\cline { 2 - 4 } & $\begin{array}{l}\text { Apropriação de valor e interesses } \\
\text { econômicos. }\end{array}$ & $\begin{array}{l}\text { Criação de valor para atendimento } \\
\text { de interesses de grupos sociais } \\
\text { vulneráveis. }\end{array}$ \\
\hline Ealor & Busca vantagens competitivas. & Busca resolver questões sociais. \\
\hline Lócus & $\begin{array}{l}\text { Desenvolvimento de } \\
\text { processos/produtos que visam a }\end{array}$ & Ações comunitárias. \\
\hline Processo & $\begin{array}{l}\text { Desenvolve-se através de etapas } \\
\text { sequenciais definidas e controladas por } \\
\text { ferramentas de gestão específicas. }\end{array}$ & $\begin{array}{l}\text { Desenvolve-se com a participação dos } \\
\text { beneficiários e dos atores da } \\
\text { comunidade durante todo o projeto, } \\
\text { sendo um processo de construção } \\
\text { social e geração de soluções através da } \\
\text { cooperação e aprendizado entre } \\
\text { todos os atores envolvidos para } \\
\text { formação de novas relações sociais. }\end{array}$ \\
\hline $\begin{array}{l}\text { Difusão do } \\
\text { conhecimento }\end{array}$ & $\begin{array}{l}\text { Mecanismos de proteção intelectual } \\
\text { procuram impedir que uma ideia ou uma } \\
\text { tecnologia desenvolvida e aplicada por } \\
\text { uma empresa possa ser copiada e } \\
\text { utilizada por } \\
\text { concorrentes. }\end{array}$ & $\begin{array}{l}\text { Seguem mecanismos de difusão que } \\
\text { favorecem a replicação e a expansão } \\
\text { dos resultados a outras comunidades. }\end{array}$ \\
\hline
\end{tabular}

Fonte: Elaborado pelos autores a partir de Bignetti (2011)

Ressalta-se que, nem sempre, a resposta a um problema social será, necessariamente, uma inovação social, pois as inovações tecnológicas podem, também, ser voltadas para a solução de problemas sociais (CAJAIBA-SANTANA, 2014), contudo estas são concebidas com interesses comerciais, distintamente das inovações sociais (DAWSON; DANIEL, 2010).

Aqui faz-se necessária, também, uma outra distinção: inovação social e empreendedorismo social. O termo inovação social remete a uma solução que cria valor para a sociedade em geral (CAIRES, 2012), ao passo em que o empreendedorismo social é o conjunto de práticas de indivíduos que possuem capacidade empreendedora e criatividade para promover mudanças sociais de longo alcance em seus campos de atividade (ASHOKA FUNDATION, 2011). Logo, a inovação social é a solução, enquanto que o empreendedorismo social é a operacionalização dessa solução. 
Por essa razão, Pol e Ville (2009) esclarecem que as inovações sociais que atendem às necessidades não satisfeitas e que não apresentam potencial de lucros são inovações sociais puras, ao passo em que a confluência da inovação social (mudança social) com ações voltadas à inovação tecnológica (interesse comercial) é denominada de inovações sociais bifocais.

Assim, a partir de ampla revisão da literatura, João (2014) esclarece que a inovação social pode ser visualizada tanto como um processo, tanto como um resultado. Enquanto processo, a inovação social preconiza a maneira como as mudanças sociais são propostas e implementadas, considerando, desta forma, a seleção, geração e implantação de ideias por pessoas que contribuem, de forma colaborativa, para o enfrentamento de desafios sociais.

Se tomada como resultado, a inovação social é legitimada pela criação de novos desenhos organizacionais, novas práticas sociais, novas estruturas de trabalho colaborativo, novos movimentos sociais, novos conhecimentos e tecnologias, assim como, pelas novas funcionalidades atribuídas a recursos e tecnologias existentes com o propósito de promover avanços sociais (CAJAIBA-SANTANA, 2014; JOÃO, 2014) e melhorias na qualidade de vida dos indivíduos (SOUZA; SILVA FILHO, 2016).

Em síntese, a inovação social sensibiliza organizações, instituições e cidadãos a arquitetar soluções coletivas para resolver problemas sociais e ambientais, quando os modelos clássicos de inovação têm sido ineficientes (WESTLEY; ANTADZE, 2010). Logo, a inovação social é a expressão de ações e praticas sociais coletivas que intencionam mudanças sociais através de mudanças de atitudes, comportamentos e percepções, resultando, assim, em novas práticas sociais (CAJAIBA-SANTANA, 2014).

Mais do que conceituar inovação social, é importante também delimitar aspectos e dimensões que facilitem sua identificação no campo empírico. Por essa razão, o próximo tópico desse trabalho, apresenta um conjunto de estudos e suas contribuições acerca das dimensões que delimitam o conceito e prática de inovação social.

\subsection{DIMENSÕES E MODELOS DE INOVAÇÃO SOCIAL}

Mesmo existindo certa regularidade, nos autores pesquisados, que a inovação social intenciona a melhoria, é necessário também apresentar mecanismos que caracterizem essa tipologia de inovação. Por este motivo este tópico apresentará alguns dos mais expressivos modelos e dimensões conceituais sobre inovação social.

O primeiro modelo apresentado é o proposto por Tardif e Harrisson (2005). A partir de estudos realizados pelo Centre de Recherche sur les Innovations Sociales - CRISES, esses autores identificaram que a inovação social está fundamentada em cinco dimensões de análise: transformação, caráter inovador, inovação, atores e processos.

Destaca-se que o CRISES é um centro institucional formado por diferentes universidades do Québec, no Canadá - e que reúne mais de 70 pesquisadores que realizam estudos sobre a inovação social (CRISES, 2016). As referidas dimensões, expostas no Quadro 2, foram definidas a partir da seleção de 49 artigos publicados pelos pesquisadores do CRISES.

Quadro 2 - Dimensões da Inovação social: Tardif e Harrisson (2005)

\begin{tabular}{|l|l|}
\hline \multicolumn{1}{|c|}{ Dimensão } & \multicolumn{1}{c|}{ Esclarecimentos } \\
\hline Transformação & Contexto que provoca o surgimento da inovação social. \\
\hline Caráter inovador & Potencial inovador da ação, produto, processo proposto. \\
\hline Inovação & $\begin{array}{l}\text { Tipologia de inovações sociais que podem ser implementadas: técnica, } \\
\text { sociotécnica, social, organizacional, institucional. }\end{array}$ \\
\hline Atores & Participantes sociais, organizacionais e/ou institucionais. \\
\hline Processo & $\begin{array}{l}\text { Meios, modos de coordenação e restrições para que o processo inovador alcance } \\
\text { os objetivos pretendidos. }\end{array}$ \\
\hline
\end{tabular}

Fonte: Elaborado pelos autores a partir de Tardif e Harrisson (2005). 
Tardif e Harrisson (2005) explicam que a dimensão "transformação" considera a conjuntura social e econômica, a partir de mudanças provocadas por crises, ruptura e descontinuidade em escalas macro e microeconômicas. Essas conjunturas funcionam como fomentadores contextuais para o aparecimento e desenvolvimento de inovações sociais.

A dimensão "caráter inovador", por seu turno, considera que as inovações se estabelecem como respostas a contextos de crises (econômicas e sociais), apresentando novas e inéditas soluções. Estas soluções são constituídas de estudos e tentativas para posterior efetivação da inovação concebida. Conforme Tardif e Harrisson (2005) essa dimensão é composta por três perspectivas de análise: Modelo - que pode caracterizado por ações sociais; Economia - tipo que se pretende a partir da inovação social; e Ação Social - iniciativas para operacionalizar a inovação social.

A dimensão "inovação" destaca a existência de diversos tipos de inovação social, tais como: inovação social técnica - emprega tecnologias com o intuito de promover melhorias para os indivíduos; sociotécnica - abrange o interesse organizacional conjuntamente com as reinvindicações sociais; social - são idealizadas e desenvolvidas por sujeitos da sociedade civil; organizacional - originadas em organizações; e institucional - resultantes da atuação do Estado.

Na dimensão "atores" estão incluídos os diversos agentes envolvidos em um processo de inovação, assim como as relações constituídas entre eles. Tardif e Harrisson (2005) apontam que esses atores podem ser: Sociais: movimentos, cooperativas, associações, sociedade civil, e sindicatos; Organizacionais: empresas, organizações de economia social, organizações coletivas, destinatários; e Institucionais: estado, identidade, valores e normas.

Por fim, a dimensão "processos" engloba a sequência de ações para efetuação da inovação social. Envolve, desta forma: os meios: relações estabelecidas entre as partes envolvidas: parcerias, integração, negociação, empowerment, difusão; os modos de Coordenação: avaliação, participação, mobilização, aprendizagem; e as Restrições: complexidade, incerteza, resistência, tensão, compromisso, rigidez institucional - para que a implementação seja bem sucedida (TARDIF; HARRISSON, 2005).

Para Souza e Silva Filho (2016), as dimensões apresentadas por Tardif e Harrisson (2005) amparam o processo de inovação social desde a elaboração, a partir de um contexto motivador, até a avaliação das ações efetuadas, num contínuo processo de aprimoramento de práticas em prol de objetivos sociais pretendidos.

Outro modelo que merece destaque é proposto por André e Abreu (2006). Segundo esses autores, a inovação social pode ser com compreendida a partir de cinco dimensões: Natureza; estímulos; recursos; dinâmicas e relações de agência. A primeira delas considera a natureza da inovação proposta, considerando, deste modo o foco da mudança, as barreiras de implementação, os processos envolvidos e os domínios econômico, tecnológico, políticos, social e cultural influentes sobre a inovação social considerada.

A segunda dimensão é chamada de estímulos e considera as adversidades, riscos, desafios e oportunidades que permitirão a identificação e implementação da inovação social. Além disso, a operacionalização da inovação social carece de recursos, os quais são apontados como a terceira dimensão, estes recursos podem ser humanos (conhecimentos e saberes), financeiros e relacionais (capacidade e alcance de interação e comunicação dos atores envolvidos no processo de inovação).

Por fim, André e Abreu (2006) defendem que a inovação social necessita de adequadas estratégias para consolidação, difusão e validação social das soluções propostas, o que é expresso nas dimensões de dinâmicas e relações de agência.

Dawson e Daniel (2010) também propuseram um modelo chamado de People, Challenge, Process, Goal no qual apresentam quatro elementos imprescindíveis à compreensão da inovação social. Esses elementos estão descritos no Quadro 3. 
Quadro 3 - Elementos de inovação social: Dawson e Daniel (2010)

\begin{tabular}{|l|l|}
\hline Elementos & \multicolumn{1}{c|}{ Caracterização } \\
\hline Pessoas & Dispostas em grupos formais ou informais. \\
\hline Desafio & Problema a ser solucionado. \\
\hline Processo & A forma como o desafio é negociado e compreendido. \\
\hline Objetivo & Resolução do desafio em prol de aumento do bem-estar coletivo. \\
\hline
\end{tabular}

Fonte: Dawson e Daniel (2010)

Dawson e Daniel (2010) explicam que o elemento "pessoas" se refere aos indivíduos que compartilham objetivos, interesses e preocupações em comum e por essa razão se envolvem em projetos de inovação social. O "desafio", por sua vez, é o problema a ser solucionado e/ou a oportunidade a ser perseguida - demanda social identificada - pelo grupo.

O "processo" é a sequência, complexa ou não, de ações que desencadearam a inovação social considerada. $\mathrm{O}$ processo é diretamente influenciado pelo ambiente social, politico e econômico no qual as pessoas estão envolvidas. Por fim, o "objetivo" é a razão pela qual o processo se realiza, com o propósito de alcançar bem-estar social, quer seja pela introdução de tecnologias inovadoras, avanços científicos ou demais práticas de cunho social coletivo.

Além de Dawson e Daniel (2010), Harrisson, Klein e Browne (2010) também apresentaram um conjunto de três dimensões, apresentadas no Quadro 4, as quais os atores definiram como relevantes ao processo de inovação social.

Quadro 4 - Dimensões da inovação social: Harrisson, Klein e Browne (2010)

\begin{tabular}{|l|l|}
\hline \multicolumn{1}{|c|}{ Dimensão } & \multicolumn{1}{c|}{ Esclarecimentos } \\
\hline Resposta a uma demanda social & $\begin{array}{l}\text { O processo de inovação está, invariavelmente, atrelado a um } \\
\text { produto social, assim processo e produto se apresentam } \\
\text { conjuntamente por meio de soluções a demandas sociais. }\end{array}$ \\
\hline Governança de inovações sociais & $\begin{array}{l}\text { Trata dos mecanismos de gestão para coordenação dos atores } \\
\text { envolvidos no processo, assim como a capacidade para promoção } \\
\text { e propagação da inovação proposta em termos de serviços e } \\
\text { produtos concebidos. }\end{array}$ \\
\hline $\begin{array}{l}\text { Transformação da democracia } \\
\text { representativa e a governança } \\
\text { democrática das instituições. }\end{array}$ & $\begin{array}{l}\text { Aspecto normativo da inovação social: identificar se as inovações } \\
\text { estão estabelecendo novos espaços democráticos, ou, apenas, } \\
\text { validando, estruturas e comportamentos existentes. }\end{array}$ \\
\hline
\end{tabular}

Fonte: Elaborado pelos autores a partir de Harrisson, Klein e Browne (2010)

Recentemente, um estudo brasileiro realizado por Silva e Bittencourt (2016), após extensa revisão da literatura, resultou na apresentação de sete dimensões para a inovação social, apresentadas e explicadas no quadro 5.

Quadro 5 - Dimensões da inovação social: Silva e Bittencourt (2016)

\begin{tabular}{|l|l|}
\hline \multicolumn{1}{|c|}{ Dimensão } & \multicolumn{1}{c|}{ Definição } \\
\hline Propósito & Satisfação de novas ou não atendidas necessidades sociais. \\
\hline Manifestação & $\begin{array}{l}\text { A inovação pode resultar em novas tecnologias, leis, modelos de negócios, } \\
\text { produtos ou serviços. }\end{array}$ \\
\hline Desenvolvimento & $\begin{array}{l}\text { Melhorar as relações e capacidades ou usar bens e recursos de uma maneira } \\
\text { nova ou melhorada. }\end{array}$ \\
\hline Envolvimento & O envolvimento das partes interessadas em um processo colaborativo e aberto. \\
\hline Coordenação & $\begin{array}{l}\text { A coordenação entre diferentes partes interessadas (indivíduos, governos, } \\
\text { entidades filantrópicas) para obter sucesso. }\end{array}$ \\
\hline Empoderamento & Capacidade da sociedade para utilizar, agir sobre a inovação social. \\
\hline Resultados & $\begin{array}{l}\text { Os resultados da inovação social criando valor social: contribuindo para a } \\
\text { superação dos desafios sociais, ambientais e econômicos, associados ao } \\
\text { paradigma do desenvolvimento sustentável. }\end{array}$ \\
\hline
\end{tabular}

Fonte: Silva e Bittencourt (2016) 
Apresentadas as dimensões para inovação social, aproveita-se dos postulados de Bignetti (2011) para sintetizar que a inovação social abarca três distintos e complementares focos para estudo: Indivíduo, organização e movimentos, apresentados no Quadro 6.

Quadro 6: Focos de pesquisa em inovação social

\begin{tabular}{|l|l|l|}
\hline \multicolumn{1}{|c|}{ Foco } & \multicolumn{1}{|c|}{ Caracterização } & Fonte de evidências \\
\hline Indivíduos & $\begin{array}{l}\text { Os estudos em inovação social consideram as ações } \\
\text { individuais de sujeitos com intenção de promover mudança e } \\
\text { bem-estar social coletivo. }\end{array}$ & $\begin{array}{l}\text { Empreendedorismo } \\
\text { social }\end{array}$ \\
\hline Organização & $\begin{array}{l}\text { A inovação social é visualizada a partir do empenho coletivo, } \\
\text { formal e estruturado, disposta pela coordenação gerencial de } \\
\text { recursos e processos. }\end{array}$ & Organizações \\
\hline Movimentos & $\begin{array}{l}\text { Ação coletiva de caráter sociopolítico de um grupo que } \\
\text { objetiva alcançar mudanças sociais. Não necessariamente, } \\
\text { disposto em estruturas formais. }\end{array}$ & Movimentos sociais \\
\hline
\end{tabular}

Fonte: Elaborado pelos autores (2019) a partir de Bignetti (2011) e Gohn (2011)

Percebe-se que as diferentes dimensões de inovação social apresentadas, mesmo com terminologias diferentes, se caracterizam em explanações semelhantes. Nesse contexto, ratifica-se que os estudos de André e Abreu (2006), Dawson e Daniel (2010), Harrisson, Klein e Browne (2010) e Silva e Bittencourt (2016) adotam dimensões equivalentes às propostas por Tardif e Harrisson (2005), como demonstrado no Quadro 7.

Quadro 07 - Dimensões de inovação social

\begin{tabular}{|l|l|l|l|l|l|}
\hline \multirow{2}{*}{ Dimensão } & \multicolumn{5}{|c|}{ ESTUDOS } \\
\cline { 2 - 6 } & $\begin{array}{l}\text { Tardif e Harrisson } \\
(2005)\end{array}$ & $\begin{array}{l}\text { André } \\
\text { Abreu (2006) }\end{array}$ & $\begin{array}{l}\text { Dawson e } \\
\text { Daniel } \\
(2010)\end{array}$ & $\begin{array}{l}\text { Harrisson } \\
(2010)\end{array}$ & $\begin{array}{l}\text { Silva } \\
\text { Bittencourt } \\
(2016)\end{array}$ \\
\hline $\begin{array}{l}\text { Fatores } \\
\text { motivadores }\end{array}$ & Transformação & Estímulos & Desafio & $\begin{array}{l}\text { Resposta a a } \\
\text { uma demanda }\end{array}$ & Proposito \\
\hline Responsáveis & Atores & $\begin{array}{l}\text { Relações de } \\
\text { agência }\end{array}$ & Pessoas & Governança & Envolvidos \\
\hline Método & Processo & $\begin{array}{l}\text { Relações de } \\
\text { agência }\end{array}$ & Processo & Governança & Coordenação \\
\hline Soluções & $\begin{array}{l}\text { Inovação/Caráter } \\
\text { inovador }\end{array}$ & ------------ & Objetivo & $\begin{array}{l}\text { Resposta a a } \\
\text { uma demanda } \\
\text { social }\end{array}$ & Resultados \\
\hline
\end{tabular}

Fonte: Elaborado pelos autores (2019)

O Quadro 7 apresenta as dimensões e terminologias apresentadas por cada grupo de autores, assim como a percepção atribuída pelos autores desse estudo, na primeira coluna, para as dimensões de inovação social.

\section{PROCEDIMENTOS METODOLÓGICO}

O objetivo desse estudo foi analisar como a inovação social tem sido caracterizada nos estudos de casos brasileiros. Para tal intento, foram listados artigos científicos publicados na base de dados Scientific Periodicals Electronic Library (SPELL), e também em anais dos congressos da Associação Nacional de Pós-Graduação e Pesquisa em Administração (ANPAD).

A ANPAD foi escolhida por desenvolver um consistente trabalho na promoção do ensino, da pesquisa e na produção de conhecimento dentro do campo das ciências 
administrativas, contábeis e afins no Brasil (ANPAD, 2019). Além disso, os anais da ANPAD foram selecionados por congregar trabalhos apresentados em relevantes eventos acadêmicos no Brasil.

Evidencia-se que a SPELL foi criada pela ANPAD. A escolha dessa base de dados foi considerada em razão da SPELL disponibilizar, de modo organizado, informações a respeito dos principais periódicos das áreas de Administração, Contabilidade e Turismo, aglomerando artigos científicos, resenhas, editoriais, notas bibliográficas, casos de ensino e debates, dentre outros documentos, todos disponíveis e de livre acesso e download (SPELL, 2019).

Destaca-se, também, que a estratégia de estudo de caso foi escolhida por ser um método de investigação empírica que averigua um fenômeno contemporâneo - inovação social - em profundidade e em seu contexto de vida real (YIN, 2015). Além disso, o estudo de caso é o método mais utilizado em pesquisas na área de administração no Brasil (LOBLER, LEHART, AVELINO, 2014).

Para a seleção dos trabalhos foram definidos como critérios básicos: Ser estudo de caso, promover a análise de inovação social, estar escrito no idioma português e apresentar casos originários do Brasil.

Os procedimentos operacionais para seleção dos estudos, conforme os critérios apresentados, se deu da seguinte forma: Inicialmente foram coletados os artigos disponibilizados no banco de dados SPELL. Os critérios para busca dos trabalhos foram definidos, inicialmente, pela existência da expressão "inovação social" no título do trabalho. Essa seleção inicial alcançou 43 trabalhos publicados entre janeiro de 2007 e agosto de 2019.

Em um segundo momento foi realizada a leitura individual do resumo de todos os 43 trabalhos com o intuito de verificar a adoção de estudos de caso para análise de inovação social, a escrita em idioma português e apresentação de casos originários do Brasil. Nessa análise constatou-se que vários artigos não contemplavam estudos de casos, apenas mencionavam o método, o mesmo aconteceu como a expressão "inovação social", quando foi identificado que nos resumos analisados, nem sempre, "inovação" e "social" apareciam como uma única expressão. Dessa segunda análise restaram 27 trabalhos.

Esses 27 trabalhos foram analisados quanto ao idioma de escrita e apresentação de casos originários do Brasil. Como a intenção de reforçar a seleção de trabalhos que adotem o estudo de caso para análise de inovação social foi verificado também o objetivo geral desses estudos. Pela verificação destes critérios alguns trabalhos foram desconsiderados. O trabalho de Sambiase, Franklin e Teixeira (2013), assim como a pesquisa de Rocha et al., (2013) foram inutilizados porque o objetivo geral se direcionava ao desenvolvimento sustentável e análise de estratégias de gestão sustentável, respectivamente, de modo que estes estudos estavam fora do escopo desta pesquisa.

O trabalho de Jimenez e Lora (2016) foi desconsiderado por estar escrito no idioma espanhol e por não deixar explícito se as evidências apresentadas eram resultantes de estudo de caso ou, somente, análise documental e revisão bibliográfica. Situação semelhante foi detectada no trabalho de Maguirre, Ruelas e Torre (2016), uma vez que o trabalho foi publicado em língua inglesa.

Adicionalmente, o trabalho de Oliveira, Melo e Muylder (2016) também foi inutilizado, pois mesmo tendo como título "Educação empreendedora: O desenvolvimento do empreendedorismo e inovação social em instituições de ensino superior", não se tratava de um caso de inovação social, mas sim de técnicas de ensino sobre o tema. Além destes, o trabalho de Vieira et al., (2018) foi inutilizado por empreender uma análise fora do contexto brasileiro, em uma associação portuguesa. Desta forma, 21 trabalhos originados da base de dados SPELL foram qualificados para a análise deste estudo.

No tocante aos anais dos eventos da ANPAD, a seleção dos trabalhos foi realizada pela busca da expressão inovação social no título dos artigos. Por esse mecanismo de busca 
foram levantados 47 estudos. Após análise individual, percebeu-se que várias metodologias de pesquisa estavam incluídas, então, após análise dos critérios básicos para inclusão nessa revisão bibliográfica (verificação da estratégia de estudo de caso, estudo em português e caso originário do Brasil) foram selecionados para avaliação 22 estudos apresentados entre janeiro de 2007 e agosto de 2019. Contudo, foi percebido que dentre os 22 estudos selecionados, 6 já haviam sido publicados e constavam na lista de estudos selecionados na base SPELL. Por essa razão, 16 artigos dos anais ANPAD foram submetidos à análise dessa pesquisa.

Na Figura 1 estão resumidos os procedimentos para seleção dos trabalhos analisados neste estudo.

Figura 1: Seleção de estudos

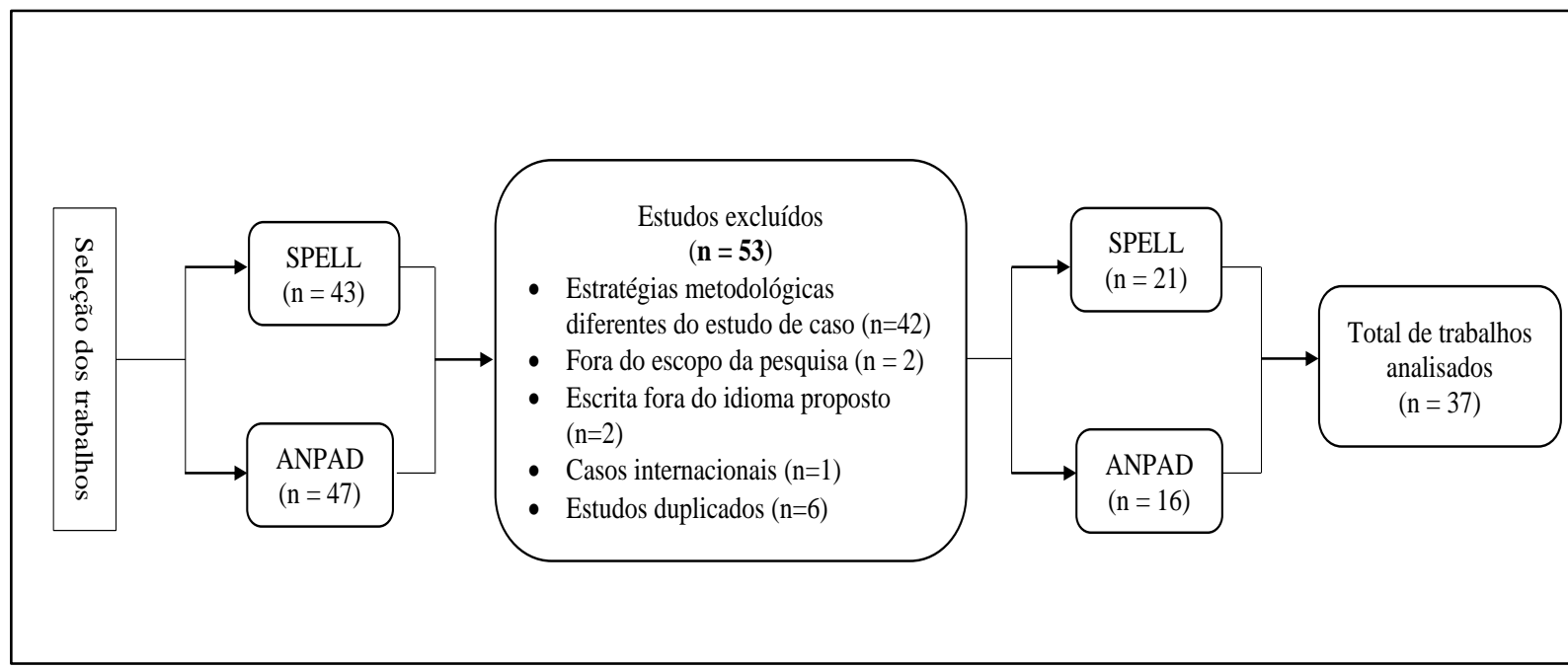

Fonte: Elaborado pelos autores (2019)

O quadro 07 sintetiza os periódicos e eventos acadêmicos consultados, o qualis CAPES ${ }^{1}$ dos periódicos e os autores utilizados. Explica-se que as siglas apresentadas no Quadro 7 referem-se a: ENANPAD - Encontro da Associação Nacional de Pós-Graduação e Pesquisa em Administração; ENEO -Encontro de Estudos Organizacionais da Associação Nacional de Pós-Graduação e Pesquisa em Administração.

Quadro 07 - Trabalhos analisados

\begin{tabular}{|c|c|l|l|l|}
\hline & Ano & \multicolumn{1}{|c|}{ Revista/Congresso } & Qualis & \multicolumn{1}{c|}{ Autor } \\
\cline { 2 - 6 } & 2007 & Revista Organizações e Sociedade & A2 & Rodrigues. \\
\cline { 2 - 6 } & 2008 & Revista Organizações e Sociedade & A2 & $\begin{array}{l}\text { Brunstein; Rodrigues; } \\
\text { Kirschbaum. }\end{array}$ \\
\cline { 2 - 6 } & 2012 & $\begin{array}{l}\text { Revista de Administração da } \\
\text { UFSM }\end{array}$ & B2 & Oliveira; Silva. \\
\cline { 2 - 6 } $\begin{array}{c}\text { Periódicos } \\
\text { acadêmicos }\end{array}$ & 2012 & $\begin{array}{l}\text { Revista Eletrônica de Gestão } \\
\text { Organizacional }\end{array}$ & B3 & $\begin{array}{l}\text { Rodrigues; Kozonoi; } \\
\text { Arruda. }\end{array}$ \\
\cline { 2 - 6 } & 2014 & $\begin{array}{l}\text { Revista de Administração da } \\
\text { UFSM }\end{array}$ & B2 & Bastos; Feldman; Fouto. \\
\cline { 2 - 6 } & 2014 & $\begin{array}{l}\text { Revista de administração pública e } \\
\text { gestão social }\end{array}$ & B1 & $\begin{array}{l}\text { Costa; Bastos; Lima; } \\
\text { Silva Filho. }\end{array}$ \\
\cline { 2 - 6 } & 2014 Hospitalar e Inovação em Saúde & B3 & Pinheiro Neto; Abreu. \\
\cline { 2 - 6 } & 2014 & $\begin{array}{l}\text { Revista Amazônia, organizações e } \\
\text { Sustentabilidade }\end{array}$ & B3 & $\begin{array}{l}\text { Silveira; Cançado; } \\
\text { Pinheiro. }\end{array}$ \\
\hline
\end{tabular}

\footnotetext{
${ }^{1}$ Sistema brasileiro de avaliação de periódicos, mantido pela Coordenação de Aperfeiçoamento de Pessoal de Nível Superior (CAPES), que relaciona e classifica os veículos utilizados para a divulgação da produção intelectual dos programas de pós-graduação do tipo stricto sensu (mestrado e doutorado).
} 


\begin{tabular}{|l|l|l|l|l|}
\hline & 2015 & Revista Gestão e Conexões & B4 & $\begin{array}{l}\text { Moura; Machado; } \\
\text { Bispo. }\end{array}$ \\
\cline { 2 - 5 } & 2015 & $\begin{array}{l}\text { Revista de Gestão Social e } \\
\text { Ambiental }\end{array}$ & B1 & $\begin{array}{l}\text { Quirino; Alvarenga Neto; } \\
\text { Carvalho; Goulart. }\end{array}$ \\
\cline { 2 - 5 } & 2016 & Revista de Administração Pública & A2 & Bittencourt; Ronconi. \\
\hline
\end{tabular}

Continua...

\begin{tabular}{|c|c|c|c|c|}
\hline \multirow{11}{*}{$\begin{array}{l}\text { Periódicos } \\
\text { acadêmicos }\end{array}$} & Ano & Revista/Congresso & Qualis & Autor \\
\hline & 2016 & $\begin{array}{l}\text { Organizações Rurais \& } \\
\text { Agroindustriais }\end{array}$ & B2 & $\begin{array}{l}\text { Freitas; Castro; Morais; } \\
\text { Vilela. }\end{array}$ \\
\hline & 2016 & Desenvolvimento em Questão & B2 & Franzoni; Silva. \\
\hline & 2016 & Revista de Gestão e Tecnologia & B3 & $\begin{array}{l}\text { Menezes; Lezana; Ronconi; } \\
\text { Menezes; Melo. }\end{array}$ \\
\hline & 2017 & $\begin{array}{l}\text { Revista Eletrônica de Estratégia e } \\
\text { Negócios }\end{array}$ & B2 & $\begin{array}{l}\text { Nunes; Casagrande; Ramos; } \\
\text { Santos; Corseuil. }\end{array}$ \\
\hline & 2018 & $\begin{array}{l}\text { Revista Perspectivas em Gestão } \\
\text { \& Conhecimento. }\end{array}$ & B1 & $\begin{array}{l}\text { Correia; Oliveira; Feitosa; } \\
\text { Goméz. }\end{array}$ \\
\hline & 2018 & Desenvolvimento em Questão & B2 & $\begin{array}{l}\text { Assunção, Kunh Júnior; } \\
\text { Ashton. }\end{array}$ \\
\hline & 2019 & Gestão \& Regionalidade & B2 & Sarate; Piccinini. \\
\hline & 2019 & Gestão \& Conexões & B4 & Cordeiro. \\
\hline & 2019 & Revista Organizações e Sociedade & $\mathrm{A} 2$ & Gonsalves; Andion. \\
\hline & 2019 & $\begin{array}{l}\text { Revista Perspectivas em Gestão } \\
\& \text { Conhecimento. }\end{array}$ & A4 & $\begin{array}{l}\text { Ribeiro; Ziviani; Corrêa; } \\
\text { Neves. }\end{array}$ \\
\hline \multirow{16}{*}{$\begin{array}{l}\text { Congressos } \\
\text { acadêmicos }\end{array}$} & 2012 & $\begin{array}{l}\text { Simpósio de Gestão da Inovação } \\
\text { Tecnológica }\end{array}$ & - & Silva. \\
\hline & 2012 & ENANPAD & - & Silva; Bignetti. \\
\hline & 2014 & $\begin{array}{l}\text { Simpósio de Gestão da Inovação } \\
\text { Tecnológica }\end{array}$ & - & $\begin{array}{l}\text { Paula; Penha; Silva Filho; } \\
\text { Souza. }\end{array}$ \\
\hline & 2016 & $\begin{array}{l}\text { Simpósio de Gestão da Inovação } \\
\text { Tecnológica }\end{array}$ & - & Galvão; Gomes. \\
\hline & 2016 & $\begin{array}{l}\text { Simpósio de Gestão da Inovação } \\
\text { Tecnológica }\end{array}$ & - & $\begin{array}{l}\text { Grando; Corseuil; } \\
\text { Machado; Casagrande. }\end{array}$ \\
\hline & 2016 & ENANPAD & - & Correia; Oliveira; Gomes. \\
\hline & 2016 & ENANPAD & - & Patias; Bobsin; Liszbinski. \\
\hline & 2016 & $\begin{array}{l}\text { Simpósio de Gestão da Inovação } \\
\text { Tecnológica }\end{array}$ & - & Silva; Bittencourt. \\
\hline & 2017 & ENANPAD & - & Correia; Oliveira; Goméz. \\
\hline & 2017 & ENANPAD & - & Geiser; parisotto; Ferrari. \\
\hline & 2018 & ENANPAD & - & Correia; Oliveira; Goméz \\
\hline & 2018 & ENANPAD & - & Torling; Resende Júnior. \\
\hline & 2018 & ENANPAD & - & Medeiros; Goméz. \\
\hline & 2018 & ENANPAD & - & $\begin{array}{l}\text { Moreira; Santos; Cabral; } \\
\text { Silva. }\end{array}$ \\
\hline & 2018 & ENANPAD & - & Souza, Segatto; Silva. \\
\hline & 2019 & ENEO & - & Silva; Silva; Bertolini; Sá. \\
\hline
\end{tabular}

Fonte: Elaborado pelos autores (2019).

Conforme inicialmente apresentado, o objetivo desse estudo foi analisar como as pesquisas do tipo estudo de caso têm abordado a inovação social. Para isso, utilizou-se as dimensões apresentadas por Tardif e Harrisson (2005). Esses autores analisaram 49 estudos desenvolvidos por pesquisadores do CRISES (Centre de Recherche sur les Innovations 
Sociales/Canadá) e chegaram a cinco dimensões da inovação social. Pela proporção do estudo realizado por esses autores, serão consideradas as dimensões por eles propostas.

Assim, as categorias para análise dos trabalhos selecionados compreenderam as dimensões de inovação social propostas por Tardif e Harisson (2005), as quais foram: transformação, caráter inovador, inovação, atores e processo.

É importante ressaltar que em virtude da variedade de conceitos atribuídos a inovação social, assim como a pouca consistência desse tema como campo de pesquisas (BIGNETTI, 2011; COSTA; DORION; OLEA, 2016), esse estudo não teve como intenção averiguar se os estudos classificados (pelos autores) como inovação social se enquadravam nos conceitos apresentados, mas sim, se os estudos que se definiam enquanto estudos de casos sobre inovação social abordavam as dimensões propostas por Tardif e Harrisson (2005).

\section{AS DIMENSÕES DE INOVAÇÃO SOCIAL NOS ESTUDOS DE CASO PUBLICADOS NO BRASIL}

A análise e discussão dos trabalhos identificados estão compiladas, inicialmente, na exposição dos aspectos gerais dos artigos, e, posteriormente, na apresentação dos resultados vinculados a cada dimensão de inovação social.

\subsection{Aspectos gerais dos artigos}

Dentre os 37 trabalhos analisados, em 30 deles a expressão inovação social estava expressa tanto no título quanto no objetivo proposto. No trabalho de Costa et al., (2014) o termo inovação social estava presente apenas no título. Em 3 trabalhos a referência à inovação social estava presente no corpo do texto, mas não explicitada nem no título e nem mesmo no objetivo.

Destaca-se o trabalho de Silveira, Cançado e Pinheiro (2014) em que a expressão inovação social é citada uma única vez ao longo do texto, quando os autores definem que a gestão social apresentada no trabalho é uma inovação social.

No trabalho de Cordeiro (2019) a expressão inovação social aparece de forma explícita no título do estudo e implícita no objetivo. Comenta-se também que nos trabalhos de Nunes et al., (2017), assim como em Assunção, Kuhn Júnior e Ashton (2018), embora a expressão inovação social apareça apenas no título dos trabalhos, os autores caracterizaram os projetos apresentados como inovações sociais.

Percebeu-se também que dentre os trabalhos publicados nos anais da ANPAD, 16 no total, 10 foram apresentados nos encontros do ENANPAD, 5 no Simpósio de Gestão da Inovação Tecnológica e 1 no Encontro de Estudos Organizacionais da ANPAD - EnEO. Desta forma, foi constatado que o ENANPAD é o evento que mais publica trabalhos sobre inovação social com estratégia metodológica do tipo estudo de caso, revelando preferência dos pesquisadores por este congresso acadêmico, dentre os eventos promovidos pela ANPAD.

Quanto aos trabalhos publicados em periódicos acadêmicos, percebeu-se que 7 foram publicados em revistas de qualis B2, 4 em revistas de qualis B3, 4 em revistas A2, 1 em revista de qualis A4, 3 em revistas B1 e 2 em revistas de qualis B4.

Quanto a concentração temporal dos 37 trabalhos analisados, evidenciou-se que 9 estudos foram publicados em 2016, 7 em 2018, 5 em 2019, 5 em 2014, 4 em 2012, 2 em 2015, 1 em 2008 e 1 em 2007, evidenciando dessa forma, ao menos nas bases consultadas, um intervalo de 3 anos, entre 2009 e 2011, e também em 2013, anos nos quais não foram publicados estudos de caso sobre inovação social.

A análise dos trabalhos de forma distinta, isto é, considerando as publicações em periódicos e em anais de congressos da ANPAD revela que os anos de 2014, 2016 e 2019 
foram os períodos com maior publicação de estudos em revistas acadêmicas, mais precisamente quatro estudos para cada um dos anos mencionados. Quanto a presença em anais de eventos da ANPAD constatou-se que os anos de 2016 e 2018 foram os mais expressivos em trabalhos com a temática de inovação social, uma vez que foram encontrados 5 registros em cada um destes anos.

\subsection{Dimensão Transformação}

Tardif e Harrisson (2005) expõem que a dimensão "transformação" se refere ao reconhecimento contextual de situações que evidenciem a necessidade de mudança. Ainda de acordo com os autores, essa dimensão deve ser analisada considerando a conjuntura local - em termos de crises, rupturas e descontinuidades; a conjuntura econômica - que envolve a produção, consumo, relações de trabalho e etc; e a conjuntura social - marcada por exclusão, marginalização, práticas vigentes e demais mudanças.

Dos 37 trabalhos analisados foi verificado que em 25 deles, a dimensão transformação havia sido contemplada, ainda que de modo parcial. É importante destacar que em nenhum dos trabalhos foi perceptível a indicação dos três contextos propostos por Tardif e Harrisson (2005), tendo sido evidenciado com maior frequência, simultaneamente, os contextos econômico e local, e local e social. O contexto econômico, de forma isolada, foi o menos reconhecido, tendo sido localizado em apenas 2 trabalhos.

Destaca-se que no trabalho de Costa et al., (2014), a dimensão transformação não foi explicitada, o texto deixa subentendido que o contexto social e econômico representados pela escassez e desperdício de água foram os responsáveis pela concepção da inovação social proposta, mas essa caracterização não ficou evidente no trabalho. Situação semelhante é constatada nos trabalhos de Gonsalves e Andion (2019) no qual existe uma análise preliminar do ambiente nacional sobre a vulnerabilidade da criança e adolescente, mas não uma indicação explícita deste contexto como desencadeador da inovação social apresentada, assim como no estudo de Medeiros e Gómez (2019) onde fica subentendido que a Microcefalia representa o contexto de transformação.

Além dos trabalhos citados, indica-se os trabalhos de Rodrigues, Kozonoi e Arruda (2012), Freitas et al., (2016), Galvão e Goméz (2016), Grando et al., (2016), Correia, Oliveira e Goméz (2016), Silva e Bittencourt (2016) e Silva et al., (2019), nos quais não foram expostas as razões e transformações pelas quais a inovação social foi desencadeada.

\subsection{Dimensão Caráter inovador}

A dimensão "caráter inovador", conforme proposta por Tardif e Harrisson (2005), se afigura como as soluções propostas em resposta à dimensão de transformação. Os autores esclarecem que o caráter inovador é expresso pela apresentação e implementação de algo novo, tais como novas formas organizacionais, novas regras sociais, novas funcionalidades e etc.

Goméz et al., (2015), em interpretação a Tardif e Harrisson (2005), explicam que o caráter inovador pode ser exposto em modelos de trabalho, desenvolvimento e governança, assim como em novidades econômicas, novidades em ações sociais como experimentos, políticas, programas, arranjos institucionais e regulamentação social.

Ao se examinarem os trabalhos considerados nesta pesquisa percebeu-se que o caráter inovador, nem sempre, ficou evidente nos casos de inovação social propostos. Explica-se que nos trabalhos de Silva e Bignetti (2012), e de Silva e Bittencourt (2016), o caráter inovador, a novidade, não foi exposto. Em verdade, esses trabalhos apresentaram uma visão gerencial de como funcionam laboratórios do tipo living labs. 
Destaca-se também o trabalho de Patias et al., (2016), que apresentaram de maneira superficial o caráter inovador da solução proposta, uma vez que esses autores apresentaram, genericamente, a criação e funcionamento de um arranjo produtivo local - APL. Os demais trabalhos analisados apresentaram, claramente, o aspecto inovador das inovações propostas, destaca-se os trabalhos de Bittencourt e Ronconi (2016) e Franzoni e Silva (2016) que deixaram exposto em seus trabalhos o caráter inovador nos modelos, nas economias e ações sociais, conforme preconizado por Tardif e Harrisson (2005).

De forma mais ampla, os trabalhos consultados que explicitaram o caráter inovador das soluções propostas, focaram expressivamente em novidades de modelos de trabalho, desenvolvimento e governança, assim como em novidades em ações sociais, principalmente, por meio de políticas e programas governamentais.

\subsection{Dimensão Inovação}

A dimensão "inovação" é a própria solução proposta a uma demanda social. Tardif e Harrisson (2005) definiram que a inovação social pode ser: Técnica/Tecnológica - resultante da utilização de tecnologias, assim como da geração de novas tecnologias, que promovem melhorias para a qualidade de vida e bem-estar social dos indivíduos; Sociotécnica conciliam interesses organizacionais e demandas sociais; Social - desenvolve soluções apresentadas por atores da sociedade civil; Organizacional - acontece dentro das organizações e, geralmente, promove melhoria da qualidade de vida dos empregados; e a Institucional aquelas que o poder público contribui de modo incisivo para concepção e implementação da solução inovadora.

Todos os trabalhos analisados explicitaram a inovação social proposta. É de ressaltar que a inovação social institucional e a inovação social foram as tipologias mais frequente nos trabalhos averiguados, uma vez que cada uma dessas tipologias de inovação foram identificadas em 10 estudos.

Evidencia-se que dentre esses 10 estudos, incluem-se os trabalhos de Paula et al., (2014), Galvão e Gomes (2016) e Franzoni e Silva (2016) que apresentaram inovações sociais e institucionais, simultaneamente. Destaca-se, também, o trabalho de Oliveira e Silva (2012) que apresentou uma inovação social que se caracterizava como institucional e sociotécnica. Merece destacar que apenas o trabalho de Bittencourt e Ronconi (2012) apresentou uma inovação de caráter, unicamente, organizacional.

Outra tipologia de inovação frequente nos trabalhos analisados foi a inovação sociotécnica que foi devidamente caracterizada em 7 estudos. Resume-se que todas as tipologias apresentadas por Tardif e Harrisson (2005) foram identificadas nos trabalhos analisados.

\subsection{Dimensão Atores}

Tardif e Harrisson (2005) explicam que a dimensão "atores" engloba todos os envolvidos nos processos de definição, concepção e implementação da inovação social. Estes atores podem ser sociais, organizacionais e institucionais. Os atores sociais representam componentes da sociedade civil, cooperativas, sindicatos e associações comunitárias. Os atores organizacionais, por sua vez, representam as empresas, organizações de economia social, empresas coletivas e empresas privadas. Os atores institucionais, por seu turno, compreendem o estado, identidade, valores e normas vigentes.

Nos casos analisados pôde ser percebido que a inovação social foi apontada como a constituição de empreendimentos responsáveis pela operacionalização do caráter inovador das soluções propostas. Assim, percebeu-se que em 13 trabalhos estavam evidenciados atores 
sociais, organizacionais e institucionais simultaneamente. Destaca-se o trabalho de Menezes et al., (2015) que não explicitou, adequadamente, quais eram os atores envolvidos no processo de inovação apresentado, ficou subentendido na leitura que se tratava de professores, estudantes e pais de alunos, o que seria configurado como atores sociais.

No caso do trabalho de Correia, Oliveira e Goméz (2016) apresenta-se com incisividade o papel dos atores organizacionais e institucionais, mas o trabalho não aponta quem representa tais atores. Por outro lado, o trabalho de Rodrigues, kozonoi e Arruda (2012) merece ser destacado, uma vez que os autores apresentam, nominalmente, as instituições e agentes organizacionais participantes do processo de inovação social estudado. Os demais estudos alternaram combinações entre atores sociais e institucionais, sociais e organizacionais e institucionais e organizacionais.

\subsection{Dimensão Processo}

A última dimensão apresentada por Tardif e Harrisson (2005) é a dimensão "processo". Segundo esses autores, essa dimensão é apresentada por meio dos modos de coordenação - avaliação, participação, mobilização e aprendizagem. É expressa em meios que se caracterizam em parcerias, integração, negociações e modos de difusão. Por fim, os processos estão expressos, também, pelas diversas restrições ao processo inovador, tais quais a complexidade, incerteza, rigidez institucional, resistência, tensão e compromisso.

A maioria dos estudos analisados apresentou e discorreu superficialmente sobre como se desenvolvia o processo de inovação social. Averiguou-se que a maioria dos estudos avaliados apresentou o processo inovador considerando os modos de coordenação, principalmente, avaliação e participação dos atores.

Além disso, o atributo mais expressivo quanto ao processo foram as parcerias, uma vez que todos os trabalhos discorreram e identificaram atores e parcerias praticadas. Contudo, alguns trabalhos foram, expressivamente, superficiais em suas descrições. $\mathrm{O}$ trabalho de Bastos, Feldan e Fouto (2014), por exemplo, evidenciou poucos aspectos de processo, permitindo identificar apenas as parcerias citadas. Merece citação, também, o trabalho de Oliveira e Silva (2012) no qual o processo inovador foi apresentado de modo genérico, subentendendo ao leitor, de modo inexpressivo, os modos de coordenação e restrição por incertezas.

Outro trabalho a ser apontado é o de Silveira, Cançado e Pinheiro (2014), no qual os autores apresentaram, mais detalhadamente, aspectos administrativos da gestão social em conselhos de saúde, não explicitamente, evidenciando o processo envolvido. Algo semelhante foi percebido no estudo de Grando et al., (2016), no qual a dimensão processo foi identificada de modo resumido, em razão dos autores terem dedicado maior atenção a apresentação de resultados e práticas organizacionais relacionadas à instituição apresentada.

Situação semelhante foi identificada no estudo de Sarate e Piccinini (2019) onde os modos de coordenação e as parcerias estão poucos explicados. Além dos estudos indicados, percebeu-se também que no trabalho de Gonsalves e Andion (2019) não há uma indicação explícita de como ocorreu o processo de inovação.

Por outro lado, nos trabalhos de Moreira et al., (2018), Torling e Resende Júnior (2018), Geiser, Parisotto e Ferrari (2017), Bittencourt e Ronconi (2016), Franzoni e Silva (2016), Moura, Machado e Bispo (2015), Pinheiro Neto e Abreu (2014), Quirino et al., (2015), e Rodrigues, Kozonoi e Arruda (2012) foi possível visualizar a dimensão processos conforme explicada por Tardif e Harrisson (2005).

Destaca-se, dentre estes, o trabalho de Franzoni e Silva (2016), que apresentou o processo de inovação social seguindo, integralmente, os aspectos propostos por Tardif e 
Harrisson (2005). Merece citação também o trabalho de Cordeiro (2019) onde estão descritos modelos e processos próprios de negócios para as inovações sociais apresentadas na pesquisa.

Sobressai, dentre os estudos analisados, a pesquisa de Correia, Oliveira e Goméz (2016), que apresentaram a inovação social considerando as dimensões de atores, necessidades sociais, processos, ganhos e respostas sociais. Mesmo adotando modelo conceitual distinto do proposto por Tardif e Harrisson (2005) foi perceptível, e devidamente identificado, os aspectos relacionados aos modos de coordenação, os meios e as restrições envolvidas no processo apresentado. $\mathrm{O}$ mesmo foi percebido no trabalho de Patias et al., (2016) no qual a inovação social foi apresentada sob o ponto de vista do processo, da formação de rede, do planejamento, da governança e dos resultados em um APL. Nesse trabalho, foram identificados aspectos de modos de coordenação e parcerias, dentre os atributos sugeridos por Tardif e Harrisson (2005).

É pertinente destacar também o estudo de Silva et al., (2019), no qual os autores apresentaram e discutiram aspectos do processo de inovação, inclusive com a indicação de estratégias, mecanismos de operação e liderança circunstancial, com destaque a participação e colaboração entre os atores apresentados no estudo.

Conforme pôde ser percebido, a dimensão processo, conforme caracterizada por Tardif e Harrisson (2005) foi perceptível nos estudos selecionados, ainda que descrita em diferentes níveis e apresentação de detalhes.

\section{CONCLUSÕES}

Este estudo se propôs a analisar como a inovação social tem sido caracterizada nos estudos de caso brasileiros publicados em periódicos de administração, ciências sociais e turismo disponibilizados na base de dados SPELL, assim como nos anais da ANPAD.

Em meio a revisão teórica percebeu-se que diferentes autores conceituaram e apresentaram características e dimensões distintivas a inovação social, dentre eles Dawson e Daniel (2010), Harrisson, Klein e Browne (2010), André e Abreu (2006), Silva e Bittencourt (2016), dentre outros. Contudo, direta e indiretamente, esses estudos acabaram ratificando o estudo de Tardif e Harrisson (2005) que propuseram que a inovação social está disposta nas dimensões de transformação, caráter inovador, inovação, atores e processo.

Inicialmente, os resultados demonstraram que, ao menos nas bases consultadas, não tem sido expressivo o número de pesquisas, com método de estudo de caso, voltados a caracterização da inovação social, uma vez que dentre os 90 estudos identificados nestas bases, 42 adotaram outras estratégias metodológicas. Revelando, desta forma, a existência de razoável número de estudos sobre inovação social, mas estes, frequentemente, são estudos teóricos sem etapas empíricas.

De forma geral, foi percebido que a partir de 2016 foram mais frequentes os estudos de casos sobre inovação social (9 trabalhos) e que embora no ano de 2017 apenas 3 trabalhos tenham sido localizados, em 2018 foram detectados 7 estudos, e em 2019, 5 artigos foram publicados, o que demonstra uma nova alta nas pesquisas sobre essa temática, especialmente ao se considerar que este estudo analisou trabalhos até agosto de 2019, existindo perspectiva para novas publicações sobre o tema até o final do ano corrente ${ }^{2}$.

No tocante ao qualis dos periódicos consultados constatou-se que aqueles classificados como "B2" foram os que mais publicaram estudos de caso sobre inovação social, mais precisamente, 7 trabalhos entre 2012 e 2019. Convém destacar que estes estudos, em sua maioria, apresentaram as dimensões de inovação social conforme proposta de Tardif e Harrisson (2005), apenas os estudos de Oliveira e Silva (2012) e Baston, Feldan e Fouto

\footnotetext{
${ }^{2}$ Refere ao ano de 2019, ano que em foi concluída a análise empreendida nessa revisão bibliográfica.
} 
(2010) não apresentaram consistentemente o contexto de transformação, ao passo em que o trabalho de Sarate e Piccinini (2019) não deixou claro o processo de inovação social, genericamente citando parcerias e modos de coordenação.

Acerca dos principais estudiosos sobre a temática de inovação social, percebeu-se que, na base de dados SPELL, Andrea Leite Rodrigues é a pesquisadora com o maior número de publicações em periódicos acadêmicos, com 3 artigos publicados nos anos de 2007, 2008 e 2012. Quanto aos anais de eventos acadêmicos da ANPAD, percebeu-se que a pesquisadora Carla Regina Pasa Goméz possui maior número de registros, uma vez que foram localizados 5 trabalhos em eventos dos anos de 2016, 2017 e 2018.

Percebeu-se também que não há concentração de estudos sobre inovação social em periódicos acadêmicos específicos, uma vez que a produção sobre essa temática está pulverizada entre os periódicos consultados, tendo sido destaque apenas as revistas Organização \& Sociedade, na qual foram localizadas 3 publicações sobre o tema, e as revistas de Administração da UFSM, Desenvolvimento em Questão, Gestão \& Conexões e Revista de Administração Pública e Gestão Social, nas quais foram identificados 2 trabalhos em cada.

Situação distinta foi percebida nos anais de eventos da ANPAD, uma vez que se percebeu concentração de estudos sobre inovação social no ENAPAND, com 10 trabalhos, e no Simpósio de inovação tecnológica com 5 registros de pesquisas sobre o tema.

Quanto à análise de dimensões de inovação social, e especificamente à dimensão transformação, percebeu-se que esta dimensão tem sido explorada nos trabalhos analisados, revelando que os pesquisadores desta temática, mesmo quando não adotam as dimensões propostas por Tardif e Harrisson (2005) contemplam elementos propostos por estes estudiosos.

Outra inferência que pode ser obtida a partir da constatação anterior, é que na maioria das vezes, ao menos nos trabalhos avaliados, o contexto que desencadeia a prática da inovação social é constituído por realidades diversas, especialmente pelas conjunturas local e econômica e econômica e social, simultaneamente.

No que se refere ao caráter inovador percebeu-se que algumas pesquisas apresentam empreendimentos sociais como inovação social, mas não destacam a novidade inserida no empreendimento analisado. Contudo, ainda que não o façam de forma explícita, a indicação de modelos de trabalho, desenvolvimento e governança podem ser classificados como caráter inovador nos estudos avaliados.

Com relação à dimensão inovação percebeu-se que as inovações institucional, sociotécnica e social são as mais descritas nos estudos avaliados. A expressiva identificação de inovação institucional revela a presença de agentes públicos como facilitadores e gerenciadores de práticas de inovação social.

Tendo em consideração a dimensão atores, a predominância de atores organizacionais, sociais e institucionais simultaneamente evidencia que a prática da inovação social tem sido resultado do trabalho colaborativo de membros da sociedade civil, de empresas e de agentes estatais.

Por fim, quanto ao processo de inovação, o que se percebe é que os modos de coordenação são poucos explorados e que aspectos relacionados às parcerias são mais discutidos, reforçando o caráter cooperativo das práticas de inovação social.

Com base nos esclarecimentos apresentados por Tardif e Harrisson (2005) percebeu-se que os estudos de caso, disponíveis na base SPELL e anais da ANPAD, tem caracterizado a inovação social conforme as dimensões propostas por esses autores. É de ressaltar que os estudos analisados não seguem uma linearidade e rigor na apresentação de dimensões de inovação social, assim como, nem sempre, apresentam as cinco dimensões propostas por aqueles autores. Destaca-se, ainda, que mesmo estudos que adotaram outros frameworks para 
caracterizar inovação social acabaram por englobar caraterísticas delimitadoras apontadas por Tardif e Harrisson (2005), a exemplo do que foi percebido no estudo de Cordeiro (2019).

Dentre as implicações teóricas, esse estudo oferece, por meio de uma revisão bibliográfica, um retrato empírico das dimensões de inovação social retratadas em estudos de casos. Além disso, a análise empreendida nessa pesquisa ratifica que fatores motivadores, responsáveis, métodos e soluções são elementos qualificadores à prática de inovação social.

As limitações metodológicas desse estudo estão associadas às bases de dados analisadas, assim como ao modelo de análise considerado. Partindo de tais limitações sugerem-se novos estudos em outras bases de dados, tais como Scopus e Scielo, assim como a utilização de outros frameworks caracterizadores da inovação social, a fim de confrontar e/ou validar os resultados aqui apresentados. Outra possibilidade para novos estudos é analisar como tem sido descrito, em estudos de caso, o impacto gerencial da inovação social.

\section{REFERÊNCIAS}

<http://www.spell.org.br/sobre/caracteristicas>. Acesso em: 30. Dez. 2016.

ANDRÉ, I.; ABREU A. Dimensões e espaços da inovação social. Finisterra, XLI, 81, pp. 121-141, 2006.

ASHOKA EMPREENDEDORES SOCIAIS; MACKISEY E CIA. INC. Empreendimentos sociais sustentáveis. São Paulo: Petrópolis, 2011.

ASSUNÇÃO, D. M.; KUHN JUNIOR, N.; ASHTON, M. S. G. Cidades Criativas e Vila Flores: Convergências e Semelhanças no Modelo de Gestão para a Inovação Social. Desenvolvimento em Questão, v. 16, n. 43, p. 291-321, 2018.

BASTOS, L. T.; FELDMANN, P. R.; FOUTO, N. M. M. D. Inovação de varejo sustentável: E-commerce e comércio justo. Revista de Administração da UFSM, v. 7, n. esp, p. 88-99, 2014.

BATAGLIN, J. C. Barreiras e facilitadores da inovação social: estudo de casos múltiplos no Brasil. 2017. 237 f. Tese (Doutorado) - Faculdade de Administração, Faculdade de Economia, Administração e Contabilidade, Universidade de São Paulo, São Paulo, 2017.

BIGNETTI, L. P. As inovações sociais: uma incursão por ideias, tendências e focos de pesquisa. Ciências Sociais Unisinos, v. 47, n. 1, p. 3 - 14, 2011.

BITTENCOURT, B. L.; RONCONI, L. F. A. Políticas de inovação social e desenvolvimento: o caso da Bolsa de Terras. Revista de Administração Pública, v. 50, n. 5, p. 795-818, 2016.

BRUNSTEIN, J.; RODRIGUES, A. L.; KIRSCHBAUM, C. Inovação social e empreendedorismo institucional: a ação da ONG "Ação Educativa" no campo educacional da Cidade de São Paulo. Organizações \& Sociedade, v. 15, n. 46, art. 6, p. 119-136, 2008.

CAIRES, J. V. Empreendedorismo social? Negócio social? Inovação social? Social good?.

Disponível em: <http://blog.impacthub.com.br/empreendedorismo-social-negocio-socialempresa-social-inovacao-social-social-good/>. Acesso em: 25 dez. 2016.

CAJAIBA-SANTANA, G. Social innovation: moving the field forward: a conceptual framework. Technological Forecasting and Social Change, v. 82, p. 42 - 51, 2014.

CAULIER-GRICE, J.; DAVIES, A; PATRICK, R; NORMAN, W. Defining Social Innovation. A deliverable of the project: "The theoretical, empirical and policy foundations for building social innovation in Europe" (TEPSIE), European Commission 7th Framework Programme, Brussels: European Commission, DG Research, 2012.

CLOUTIER, J. 2003. Qu'est-ce que l'innovation sociale? Crises, ET0314. Disponível em: <www.crises.uqam.ca>. Acesso em: 18/12/2016.

CORDEIRO, K. L.Questões Centrais do Processo de Inovação Social no Brasil . Gestão \& Conexões, v. 8, n. 2, p. 105-117, 2019. 
CORREIA, S. E. N.; OLIVEIRA, V. C.; GOMÉZ, C. R. P. Cooperando para fortalecer: O papel dos atores organizacionais e suas relações interinstitucionais nas iniciativas de inovação social. In: Encontro Nacional da ANPAD, 2018, Curitiba. Anais... Curitiba: ENANPAD, 2018.

CORREIA, S. E. N.; OLIVEIRA, V. C.; GOMÉZ, C. R. P. O papel do ator organizacional no processo de inovação social. In: Encontro Nacional da ANPAD, 2017, São Paulo. Anais... São Paulo: ENANPAD, 2017.

CORREIA, S. E. N.; OLIVEIRA, V. C.; GOMÉZ, C. R. P. O papel do ator organizacional no processo de inovação social. In: Encontro Nacional da ANPAD, 2016, Costa do Sauipe. Anais... Costa do Sauipe: ENANPAD, 2016.

CORREIA, S. N.; OLIVEIRA, V. M.; FEITOSA, M. J. S.; GÓMEZ, C. R. P. Inovação Social para o Desenvolvimento Sustentável: Um Caminho Possível. Administração Pública e Gestão Social, v. 10, n. 3, p. 199-212, 2018.

COSTA, J. S.; BASTOS, G. M. F.; LIMA, B. C. C.; SILVA FILHO, J. C. L. Inovação social, prazer e sofrimento no trabalho: o caso do Projeto Mandalla no Ceará. Administração Pública e Gestão Social, v. 6, n. 1, p. 11-18, 2014.

COSTA, L. F.; DORION, E. C. H.; OLEA, P. M. Produção Acadêmica Sobre Inovação Social em Programas de Mestrado e Doutorado Brasileiros. In: XVI MOSTRA DE INICIAÇÃO CIENTIFICA, PÓS-GRADUAÇÃO, PESQUISA E EXTENSÃO, 2016, Caxias do Sul. Anais... Caxias do Sul: UCS, 2016.

CRISES - Centre de recherche sur les innovations sociales. ANDREW, Caroline; KLEIN, Juan-Luis. Social Innovation: What is it and why is it important to understand it better. Disponível em: < http://crises.uqam.ca/upload/files/publications/etudes-theoriques/>. Acesso em: 20 jul. 2013.

CRISES. $\mathrm{Na}$ Introduction to CRISES. Disponível em: <http://crises.uqam.ca/upload/files/presentation/P_CRISES_ang.pdf>. Acesso em: 21. Dez. 2016.

DAWSON, P.; DANIEL, L. Understanding social innovation: a provisional framework. International Journal of Technology Management, v. 51, n. 1, p. 9 - 21, 2010.

ECHEVERRÍA, J. El manual de Oslo y la innovación social. ARBOR Ciencia, Pensamiento y Cultura, v. 184, n. 732, p.609-618, 2008.

FLEURY, S. Programa de Estudos sobre a Esfera Pública - PEEP. Disponível em Acesso em: 25 abr. 2011.

FRANZONI, G. B.; SILVA, T. N. Inovação Social e Tecnologia Social: O Caso da Cadeia Curta de Agricultores Familiares e a Alimentação Escolar em Porto Alegre/RS. Desenvolvimento em Questão, v. 14, n. 37, p. 353-386, 2016.

FREITAS, R. C.; CASTRO, C. C.; MORAIS, R.; VILLELA, B. A. Interorganizational Relationships in Groups of Small Family Farmers in South of Minas Gerais: Critical Reflections and Social Innovations. Organizações Rurais \& Agroindustriais, v. 18, n. 1, p. 39-51, 2016.

GALVÃO, C. E. S.; GOMÉZ, C. R. P. Protagonismo dos atores na Inovação social:O Caso do Projeto Jovens Radialistas do Semiárido. In: XXIX SIMPÓSIO DE GESTÃO DA INOVAÇÃO TECNOLÓGICA, 2016, São Paulo. Anais...São Paulo, 2016.

GEISER, C. M. G.; PARISOTTO, I. R. S.; FERRARI, D. Projeto de equoterapia sob a perspectiva das dimensões de inovação social. In: Encontro Nacional da ANPAD, 2017, São Paulo. Anais... São Paulo: ENANPAD, 2017.

GOHN, M. G. Movimentos sociais na contemporaneidade. Revista Brasileira de Educação, v. 16 n. 47 maio-ago. 2011. 
GONSALVES, A. K. R.; ANDION, M. C. M. Ação Pública e Inovação Social: Uma Análise do Sistema de Garantia de Direitos da Criança e do Adolescente de FlorianópolisSC. Organizações \& Sociedade, v. 26, n. 89, p. 221-248, 2019.

GRANDO, V. S.; CORSEUIL, L.; MACHADO NETO, D. D. P.; CASAGRANDE, J. L. Práticas Organizacionais associadas à Inovação Social: Aplicação no Instituto Comunitário de Florianópolis. In: XXIX SIMPÓSIO DE GESTÃO DA INOVAÇÃO TECNOLÓGICA, 2016, São Paulo. Anais...São Paulo, 2016.

HARRISON, D.; KLEIN, JUAN-LUIS; BROWNE, P. L. Social innovation, social entreprise and services. In: GALLOUJ, Faïz; DJELLAL, Faridah (Eds). The Handbook of Innovation and Services. Cheltenham, UK: Edward Elgar, p.197-218, 2010.

HAVE, R. P. V. D.; RUBALCABA, L. Social innovation research: An emerging area of innovation studies? Research Policy, v. 45, p. 1923-1935, 2016.

JIMÉNEZ, D. R.; LORA, P. La Innovación Social Como Transformación de Comunidades: El Modelo Del Parque Cientifico De Innovación Social-Colombia. NAVUS - Revista de Gestão e Tecnologia, v. 6, n. 4, p. 88-97, 2016.

JOÃO, I. S. Modelo de gestão da inovação social para empresas sociais. 2014. Tese (Doutorado em Administração) - Universidade de São Paulo. Ribeirão Preto, 2014.

LACERDA, L. F. B.; FERRARINI, A. F. Inovação social ou compensação? Reflexões acerca das práticas corporativas. Polis, v. 35, 2013.

LÖBLER, M. L.; LEHNHART, E. R.; AVELINO, A. F. A. Como estão sendo Conduzidos os Estudos De Caso? Uma Reflexão Sobre os Trabalhos Publicados na Área de Administração. In: XXXVIII Encontro da ANPAD, 2014, Rio de Janeiro. Anais...Rio de Janeiro, 2014.

LUBELCOVÁ, G. Social innovations in the context of modernization. Sociológia, v. 44, n. 3, p. 291-313, 2012.

MAURER, A. M. As dimensões de inovação social em empreendimentos econômicos solidários do setor de artesanato gaúcho. 2011, 191 f. Dissertação (Mestrado em Administração) - Escola de Administração. Universidade Federal do Rio Grande do Sul, Porto Alegre, 2011.

MEDEIROS, C. B.; GOMÉZ, C. R. P. A disseminação de uma iniciativa de inovação social. In: Encontro Nacional da ANPAD, 2018, Curitiba. Anais... Curitiba: ENANPAD, 2018.

MENEZES, A. G.; LEZANA, A. G. R.; RONCONI, L. F. A.; MENEZES, E. C. O.; MELO. N. A pesquisa-ação como estratégia de avaliação da inovação social: estudo de uma entidade educacional do município de Florianópolis. NAVUS - Revista de Gestão e Tecnologia, v. 6, n. 2, p. 93-105, 2016.

MOREIRA, T. P.; SANTOS, S. M.; CABRAL, A. C. A.; SILVA, N. M. N. Dimensões da inovação social: o caso da fundação Casa Grande - Memorial do homem Kariri. In: Encontro Nacional da ANPAD, 2018, Curitiba. Anais... Curitiba: ENANPAD, 2018.

MOURA, E. O.; MACHADO, A. G. C.; BISPO, M. S. O microcrédito como fomentador de uma infraestrutura comercial voltada para a base da pirâmide: o caso do programa empreender bananeiras. Gestão \& Conexões, v. 4, n. 2, p. 84-104, 2015.

MULGAN, G.; TUCKER, S.; SANDERS, B. 2007. Social Innovation: What It Is, Why It Matters and How It Can Be Accelerated.London, The Young Foundation. Disponível em: <www.youngfoundation.org>. Acesso em: 23/12/2016.

MURRAY, R.; CAULIER-GRICE, J.; MULGAN, G. 2010. The Open Book of Social Innovation. London, NESTA/The Young Foundation. Disponível em: <www.nesta.org.uk/publications/assets/features/the_open_book_of_social_innovation>.

Acesso em: 18/12/2016.

NUNES, N. A.; CASAGRANDE, J. L.; RAMOS, M. M. G.; SANTOS, A. A. P.; CORSEUIL, L. Participação Comunitária como Prática de Inovação Social: Um Estudo de 
Caso no Centro Educacional Marista Lúcia Mayvorne. Revista Eletrônica de Estratégia \& Negócios, v. 10, n. 2, p. 154-180, 2017.

OLIVEIRA, A. G. M.; MELO, M. C. O. L.; MUYLDER, C. F. Educação empreendedora: o desenvolvimento do empreendedorismo e inovação social em instituições de ensino superior. Revista Administração em Diálogo, v. 18, n. 1, p. 29-56, 2016

OLIVEIRA, N. D. A.; SILVA, T. N. Inovação social e tecnologias sociais sustentáveis em relacionamentos intercooperativos: um estudo exploratório no CREDITAG-RO. Revista de Administração da UFSM, v. 5, n. 2, p. 277-295, 2012.

PATIAS, T. Z.; BOBSIN, D.; LISZBINSKI, B. B.; DAMKE, L. I.; FRIZZO, K. Arranjos produtivos locais da agroindústria familiar sob a otica da inovação social. In: XL ENCONTRO DA ENANPAD, 2016, Costa do Sauipe. Anais... Costa do Sauipe, 2016.

PATIAS, T. Z.; GOMES, C. M; LISZBINSKI B. B.; KNEIPP, J. M.; BOBSIN, D. A Constituição da Inovação Social como Campo de Pesquisa: um Resgate Teórico e uma Agenda para Trabalhos Futuros. In: Encontro da ANPAD, 2015, Belo Horizonte. Anais...Belo Horizonte, 2014.

PAULA, E. V. de; PENHA, E. D. S.; SILVA FILHO, J. C. L.; SOUZA, L. C. L. A inovação social e o desenvolvimento sustentável na algicultura: o caso do projeto mulheres de corpo e alga. In: SIMPÓSIO DE GESTÃO DA INOVAÇÃO TECNOLÓGICA, 2014, Belo Horizonte. Anais...Belo Horizonte, 2014.

PINHEIRO NETO, G. F.; ABREU, M. C. S. Inovação social em um empreendimento econômico solidário: alternativas para o enfrentamento da marginalização . Revista de Administração Hospitalar e Inovação em Saúde, v. 12, n. 2, p. 1-18, 2015.

POL, E.; VILLE, S. Social innovation: buzz word or enduring term? Journal of SocioEconomics, v.38, p. 878-885, 2009.

PUE, K.; VANDERGEEST, C.; BREZNITZ, D. Toward a Theory of Social Innovation. Innovation Policy Lab White Paper, 2016.

QUIRINO, B. S.; ALVARENGA NETO, R. C. D.; CARVAlHO, R. B.; GOULART, B. Análise do Programa Habitacional Minha Casa, Minha Vida nas Perspectivas da Inovação Social e a Evolução das Políticas Públicas. Revista de Gestão Social e Ambiental, v. 9, n. 3, p. 97-117, 2015.

RIBEIRO, J. S. A. N.; ZIVIANI, F.; NEVES, J. T. R.; CORREA, F. Inovação Social e Gestão do Conhecimento Estratégico: Estudo de Caso na Cadeia de Suprimentos Reversa. Perspectivas em Gestão \& Conhecimento, v. 9, n. 1, p. 285-302, 2019.

RODRIGUES, A. L.; KOZONOI, N.; ARRUDA, F. A. M. Organizações sociais: um estudo de caso sobre possibilidades e limitações da geração de inovação social pela OSESP. GESTÃO.Org - Revista Eletrônica de Gestão Organizacional, v. 10, n. 2, p. 344344, 2012.

RODRIGUES, A. L. Modelos de gestão e inovação social em organizações sem fins lucrativos: divergências e convergências entre nonprofit sector e economia social. Organizações \& Sociedade, v. 14, n. 43, p. 111-128, 2007.

SARATE, J. A.; PICCININI, V. C. Inovação Social e Desenvolvimento Territorial. Gestão \& Regionalidade, v. 35, n. 105, p. 106-122, 2019.

SILVA, M. S.; SILVA, M. G.; BERTOLINI, O. T.; SÁ, M. R. Governança no processo e inovação social sob a lente da visão relacional: um estudo de caso na Convexo Lab. In: Encontro de estudos organizacionais da ANPAD, 2019, Fortaleza. Anais... Fortaleza: ENEO, 2019.

SILVA, S. B da; BIGNETTI, L. P. A Inovação Social e a Dinâmica de Inovação Aberta na Rede Brasileira de Living Labs. In: ENCONTRO DA ENANPAD, 2012, Rio de Janeiro. Anais... Rio de Janeiro, 2012. 
SILVA, S. B. Inovação Social Corporativa: Um Estudo de Caso no Instituto Nokia de Tecnologia. In: SIMPÓSIO DE GESTÃO DA INOVAÇÃO TECNOLÓGICA, 2012, Salvador. Anais... Salvador, 2012.

SILVA, S. B.; BITENCOURT, Claudia Cristina. Inovação Social Aberta: Estudo sobre Inovações Sociais em Living Labs. In: XXIX SIMPÓSIO DE GESTÃO DA INOVAÇÃO TECNOLÓGICA, 2016, São Paulo. Anais...São Paulo, 2016.

SILVEIRA, T. S.; CANÇADO, A. C.; PINHEIRO, L. S. A participação no Conselho Municipal de Saúde de Imperatriz-MA na perspectiva da gestão social e da cidadania deliberativa. Amazônia, Organizações e Sustentabilidade, v. 3, n. 1, p. 45-60, 2014.

SOUZA, A. C. A. A.; SILVA FILHO, J. C. L.. Dimensões da Inovação Social e Promoção do Desenvolvimento Econômico Local no Semiárido Cearense. In: XXXVIII Encontro da ANPAD, 2014, Rio de Janeiro. Anais...Rio de Janeiro, 2014.

SOUZA, I. G. B.; SEGATTO, A. P.; SILVA, R. L. M. As fases do processo de inovação social: um estudo no contexto dos negócios de impacto. In: Encontro Nacional da ANPAD, 2018, Curitiba. Anais... Curitiba: ENANPAD, 2018.

TARDIF, C; HARRISSON, D. Complémentarité, convergence e transversalité: La conceptualization de l'innovationsocialeau CRISES. IN: CRISES. Centre de RechercheSurLesInnovationSociales. Cahiers du CRISES. Québec, 2005.

TORLING, E. G. S.; RESENDE JÚNIOR, P. C. Projeto de controle social sob a perspectiva das dimensões de inovação social: Uma discussão sobre a cocriação e o valor percebido pelos atores sociais. In: Encontro Nacional da ANPAD, 2018, Curitiba. Anais... Curitiba: ENANPAD, 2018.

Turismo de Base Comunitária como Inovação Social: congruência entre os constructos.

WARNOCK, R. Harnessing the power of social innovation to drive the Northern Ireland economy - Final draft. Department of Enterprise, Trade and Investment - DETI, 2014. Disponível em: <http://outhouseconsulting.co.uk/research/4575037824>. Acesso em: 15/12/2016.

WESTLEY, F.; ANTADZE, N. Making a difference: strategies for scaling social innovation for greater impact. The Innovation Journal: The Public Sector Innovation Journal, v. 15, n. 2, p. 2-18, 2010.

YIN, R. K. Estudo de caso. 5. ed. Porto Alegre: Bookman, 2015. 